University of Wollongong

Research Online

Faculty of Business - Papers (Archive)

Faculty of Business and Law

$1-1-2014$

A critical reflection on the role of stakeholders in sustainable tourism development in least-developed countries

Sotear Ellis

Edith Cowan University

Lynnaire Sheridan

University of Wollongong, lynnaire.sheridan@otago.ac.nz

Follow this and additional works at: https://ro.uow.edu.au/buspapers

Part of the Business Commons

Research Online is the open access institutional repository for the University of Wollongong. For further information contact the UOW Library: research-pubs@uow.edu.au 


\title{
A critical reflection on the role of stakeholders in sustainable tourism development in least-developed countries
}

\author{
Abstract \\ While investigating the implementation of community-based tourism in least-developed countries (LDCs), \\ the critical role of stakeholders in sustainable tourism development became apparent. External \\ stakeholders, in particular, develop theory models and define policy for translation into the field yet there \\ is little critical consideration of their role and influence. This article encapsulates insights achieved by the \\ researchers at the interface of theory and practice in a challenging LDC setting.

\section{Keywords} \\ reflection, critical, least, development, countries, tourism, developed, sustainable, stakeholders, role \\ Disciplines \\ Business

\section{Publication Details} \\ Ellis, S. \& Sheridan, L. (2014). A critical reflection on the role of stakeholders in sustainable tourism \\ development in least-developed countries. Tourism Planning \& Development, 11 (4), 467-471.
}




\title{
A critical reflection on the role of stakeholders in sustainable tourism development in Least Developed Countries
}

\author{
While investigating the implementation of community based tourism in Least \\ Developed Countries (LDC), the critical role of stakeholders in sustainable tourism \\ development became apparent. External stakeholders, in particular, develop theory \\ models and define policy for translation into the field yet there is little critical \\ consideration of their role and influence. This article encapsulates insights achieved by \\ the researchers at the interface of theory and practice in a challenging LDC setting.
}

\section{Keywords}

Sustainable tourism, Least Developed Countries, stakeholder conflicts, tourism development

\section{What is sustainable tourism? The role of stakeholders in setting the agenda}

According to the World Tourism Organisation definition:

\begin{abstract}
"Sustainable tourism development meets the needs of present tourists and host regions while protecting and enhancing opportunities for the future. It is envisaged as leading to the management of all resources in such a way that economic, social and aesthetic needs can be fulfilled while maintaining cultural integrity, essential ecological processes, biological diversity, and life support systems.” (World Tourism Organization, 1998, p.
\end{abstract} 20)

While this overarching definition exists, the many theoretical and practical stakeholders involved have led to a proliferation of interpretations (Gilmore, Carson and Ascenco, 2007; Kelly and Moles, 2000). Ironically, the emerging products do not always manifest sustainable tourism’s original intent. For example, an ecological product might establish good market growth but if there are negative community impacts, it has not achieved sustainable tourism’s holistic benefits (Jamrozy, 2007;Lansing and De Vries, 2007; Tepelus, 2008). Where projects are ecologically and socio-culturally appropriate they might 
become untenable; struggling to sustain multiple expectations and therefore fail - which defeats the purpose.

To date, there has been too little consideration of the role stakeholder's play in the concept of sustainable tourism and its practice in the field. External stakeholders (the academics, industry and NGOs operating outside of communities) are fundamentally shaping the theoretical foundations of the sustainable tourism concept. They define the 'ideal' and propose best practice models for implementation. While they provide essential guidance for the collective understanding of sustainable tourism, this 'ideal' often does not address issues faced by internal (NGO and community) stakeholders in the field (Teye, Sonmez and Sirakaya, 2002).

If sustainable tourism cannot be achieved long-term in the field, in certain scenarios, perhaps the validity of ideas posited by external stakeholders should be questioned rather than suspecting that communities were unsuitable or practitioners incapable. At the very least if strong success cannot be demonstrated, it is proposed here that the appropriateness of implementing sustainable tourism models in the world's most vulnerable LDC communities, in lieu of broader development goals, should be seriously considered.

The main issue in LDCs appears to be the people versus conservation interface. Principally, when sustainable tourism is used as a development tool for LDC communities, the pressure is on to generate fast returns on tourism development and achieve long term industry sustainability with widespread community benefits (World Tourism Organisation, 2005). This conflicts with the persistent external emphasis on the conservation of physical resources, derived from the historical foundations of sustainability in forestry and natural resource management (Pokharel and Larsen, 2007; Searcy, Karapetrovic and McCartney, 2005; Sherry, Halseth, Fondahl, Karjala and Leon, 2005). Natural resources are frequently re-tasked as tourism assets or, at a minimum, tourism is supporting education and support for 
conservation (World Tourism Organisation, 2005). These natural resources are, however, often the same resources communities would like to use for immediate poverty alleviation.

Moreover, LDCs are already a highly complex setting for any tourism, let alone a product challenged to meet the multiple, perhaps conflicting, goals set out by the stakeholders involved. It is common in LDCs for third parties (NGOs or, sometimes, government authorities) to propose sustainable tourism yet these organisations might operate from a domestic capital, or even another country, to implement projects in the poorest and most isolated areas of LDCs (Carbone, 2005; Manyara and Jones, 2007;Stoeckl, 2007; Buccus, Hemson, Hicks, and Piper, 2008). NGOs typically have fragile funding yet, often underfunded, they then also negotiate local customs, processes and authorities to achieve outcomes (Coate, Handmer, and Choong, 2006; Gounder, 2001;Feng, 2008; Hanh, 2006; Jayawardena, Patterson, Choi and Brain, 2008). Even national governments confront issues related to the unique cultural and community aspects of an area (Chens, Sok and Sok,2008; Teye et al., 2002). As a consequence, often external consultants are brought due to their expertise to address the complexities of community and cultural analysis required for tourism development.

Unfortunately, the current reality for community development consultancy is its Formatted: New paragraph corporatisation with external consulting companies trying to match funding body price-points by offering community assessments using rapid appraisal techniques. -While even anthropological fieldwork experts emphasise that "Not everything needs to be counted and measured..." (Wolcott, 1995, p.15), it is still important to determine what is unique to any given setting and should therefore be considered, captured and evaluated, however, there is an increasingly small window of opportunity for consultants to do this before flying out to the next country, culture and community context.- Within these constraints, "The real genius in 
fieldwork lies in knowing how to answer that seemingly simple question: 'What counts?' "' (Wolcott, 1995, p.18).

The issues surrounding rapid rural appraisal for tourism are not new, indeed there was reference to them in a 1979 Institute of Development Studies conference where Robert

Chambers, a leadering advocate for Rapid Rural Appraisal, is mentioned as being concerned about this method being used for 'rural development tourism' (Stocking 1980). After all, his idea was that "Decision makers need the right information at the right time... in a cost efficient way." (Chambers, 1981, p. 95) No one endorses the wrong information in a timely manner.

In a world where time is money, communities primed for tourism are rapidly assessed, 'sustainable' tourism plans are developed and then, at some point in the future (if funding is obtained), implementation occurs - meanwhile community momentum may be lost, and many of the crucial benefits implementation was to provide along with it.- Indeed, the conundrum of time - taking the time to understand, the time lag for implementation and timing when the community is ready for external stakeholders to pull out - is a challenge for all sustainable tourism advocates to consider.

Even when time is invested and the most appropriate appraisal approach is undertaken, the impact of power imbalances in LDCs between local people and their $\underline{\text { domestic leaders and/or external stakeholders cannot be ignored. -Indeed the authors }}$ discovered in their research that, at times, participants were not willing to comment as they feared their opinion might vary from that of officials, and, in other cases, people would say what they thought should be said.

Overall, So, the complexity of sustainable tourism implementation in LDCs cannot be under-estimated. 
The researchers propose that, in the field in LDCs, the philosophy of sustainable tourism development is met with community development goals. Practitioners look to the many theoretical concepts and struggle to draw out a model suited to their scenario (hence the emergence of mismatched products that do not meet sustainable tourism's intent). The combination of external stakeholder views and poor internal stakeholder translation means that the stakeholders themselves become a source of challenges to the practical implementation of sustainable tourism. Transparent consideration of the external and internal stakeholder interface may help these challenges be addressed in the community setting and, perhaps, projects where this occurs have a chance at success. This perspective on the critical role of stakeholders in the process from sustainable tourism development theory to its practical implementation in LDCs is depicted in Figure 1.

Figure 1. Theoretical framework underpinning the practical application of sustainable tourism in LDCs

So while communities are often considered responsible for the outcomes (positive or negative) of sustainable tourism development, some consideration of the role of stakeholders and their conflicting perspectives would appear to be warranted. Indeed, it may also be appropriate to attempt to identify settings where sustainable tourism is unlikely to be fully achieved - where it is inspirational rather than practical.

In conclusion, the inconsistencies in sustainable tourism theory and practice can be largely attributed to the influences of the external and internal stakeholders involved. The potential impact is augmented in LDCs as these are more vulnerable communities. Recognition of stakeholder influences and effects could lead to the reconciliation of these inconsistencies with acceptance of some of the inevitabilities and the introduction of processes to minimise their effects. A model which reflects the practical implication of 
stakeholder involvement in sustainable tourism development has been presented to elucidate this issue.

Despite the challenges identified, the role of sustainable tourism for LDC development is still important as it is less resource-heavy compared to other industries. This critique serves to highlight the realities of sustainable tourism for development in LDCs to avoid unrealistic expectations of sustainable tourism in practice and to stimulate the consideration of more practical models of sustainable tourism for development which address stakeholder conflicts effectively.

\section{References}

Buccus, I., Hemson, D., Hicks, J., \& Piper, L. (2008). Community Development and Engagement with Local Governance in South Africa. Community Development Journal, 43, 297-311.

Carbone, M. (2005). Sustainable Tourism in Developing Countries: Poverty Alleviation, participatory planning, and ethical issues. The European Journal of Development Research, 17, 559-565.

Chambers, R. (1981). Rapid rural appraisal: rationale and repertoire. Public Administration \& Development, 13, 95 - 106.

Chens, C.-Y., Sok, P., \& Sok, K. (2008). Evaluating the Competitiveness of the Tourism Industry in Cambodia: Self-assessment from professionals. Asia Pacific Journal of Tourism Research, 13, 41-66.

Coate, B., Handmer, J., \& Choong, W. (2006). Taking Care of People and Communities: Rebuilding livelihoods through NGOs and the informal economy in Southern Thailand. Disaster Prevention and Management, 15, 135.

Feng, X. (2008). Who Benefits?: Tourism Development in Fenghuang County, China. Human Organization, 67, 207.

Gilmore, A., Carson, D., \& Ascenco, M. (2007). Sustainable Tourism Marketing at a World Heritage Site. Journal of Strategic Marketing, 15, 253-264.

Gounder, R. (2001). An Empirical Investigation of Development Assistance and Growth for the Case of Fiji. International Journal of Social Economics, 28, 278-294. 
Hanh, V. T. H. (2006). Canal-side Highway in Ho Chi Minh City (HCMC), Vietnam: Issues of urban cultural conservation and tourism development, GeoJournal, 66, 165.

Jamrozy, U. (2007). Marketing of Tourism: A paradigm shift toward sustainability. International Journal of Culture, Tourism and Hospitality research, 1, 117-130.

Jayawardena, C., Patterson, D. J., Choi, C., \& Brain, R. (2008). Sustainable Tourism Development in Niagara. International Journal of Contemporary Hospitality Management, 20, 258-277.

Kelly, R., \& Moles, R. (2000). Towards Sustainable Development in the Mid-West Region of Ireland. Environmental Management and Health, 11, 422-432.

Lansing, P., \& De Vries, P. (2007). Sustainable Tourism: Ethical alternative or marketing ploy? Journal of Business Ethics, 72, 77.

Manyara, G., \& Jones, E. (2007). Community-based Tourism Enterprise Development in Kenya: An exploration of their potential as avenues of poverty reduction., Journal of Sustainable Tourism, 15, 628-644.

Pokharel, R. K., \& Larsen, H. O. (2007). Local vs Official Criteria and Indicators. Forestry, 80, 183-192.

Searcy, C., Karapetrovic, S., \& McCartney, D. (2005). Designing Sustainable Development Indicators: Analysis for a case utility. Measuring Business Excellence, 9, 33-41.

Sherry, E., Halseth, R., Fondahl, G., Karjala, M., \& Leon, B. (2005). Local-level Criteria and Indicators. Forestry, 78, 513-539.

Stocking, M. (1980). Rapid Rural Appraisal: Quick-and-Dirty v. Long-and-Clean. Area, (12), 235.

Stoeckl, N. (2007). Regional Expenditure Patters, Remoteness and Type of Enterprise: Which tourism businesses spend the largest amount within their local communities?, Economic Papers - Economic Society of Australia, 26, 64.

Tepelus, C. M. (2008). Social Responsibility and Innovation on Trafficking and Child Sex Tourism: Morphing of practice into sustainable tourism policies?, Tourism and Hospitality Research, 8, 98-115.

Teye, V., Sonmez, S. F., \& Sirakaya, E. (2002). Residents' Attitudes Towards Tourism Development, Annals of Tourism Research, 29, 668-688.

Wolcott, H. (1995). The Art of Fieldwork. Walnut Creek: AltaMira Press.

World Tourism Organisation. (2005). Indicators of Sustainable Development for Tourism Destinations: A guidebook. Madrid, Spain: World Tourism Organisation. 
World Tourism Organization. (1998). Guide for Local Authorities on Developing Sustainable Tourism. Madrid, Spain: World Tourism Organization. 
Figure 1. Theoretical framework underpinning the practical application of sustainable tourism in LDCs 